\title{
Hurler Syndrome
}

\author{
Rao KS ${ }^{1}$, Adhikari $\mathrm{S}^{2}$, Singh $\mathrm{S}^{3}$, Poudel $\mathrm{S}^{4}$, Basnet $\mathrm{S}^{5}$, Bishwakarma $\mathbf{G}^{6}$
}

${ }^{1}$ Dr. Kalipatanam Seshagiri Rao, MBBS, DCH. MD. Professor and head of Paediatrics, Manipal Teaching Hospital, Manipal College of Medical Sciences, Pokhara Nepal, ${ }^{2}$ Dr. Sudhir Adhikari, MBBS. MD. Assistant Professor, Department of Paediatrics, Manipal Teaching Hospital, Manipal College of Medical Sciences, Pokhara Nepal. ${ }^{3}$ Dr. Sandeep Singh, MBBS. MD. Lecturer, Noble Medical College, Biratnagar, Nepal. ${ }^{4}$ Dr. Shankar Poudel, MBBS, MD, Lecturer, Gandaki Medical College, Pokhara, Nepal, ${ }^{5} \mathrm{Dr}$. Sahisnuta Basnet MBBS, MD, Assistant Professor, Department of Paediatrics, Manipal Teaching Hospital, Manipal College of Medical Sciences, Pokhara Nepal, ${ }^{6} \mathrm{Dr}$. Ganesh BK, MBBS. MD.Lecturer, Department of Paediatrics, Manipal Teaching Hospital, Manipal College of Medical Sciences, Pokhara Nepal.

Address for correspondence:

Dr. KS Rao

E-mail: dr ksrao29@ hotmail.com

\section{How to cite}

Rao KS, Adhikari S, Singh S, Poudel S, Basnet S, Bishwakarma G. Hurler Syndrome. J Nepal Paediatr Soc 2016;36(3):295-297.

doi: http://dx.doi.org/10.3126/jnps.v36i3.16349

This work is licensed under a Creative Commons Attribution 3.0 License.

\begin{abstract}
We report a case of Hurler syndrome in 10 years old boy diagnosed on the basis of classical clinical and radiological features. Early diagnosis, genetic counseling and regular follow up with recent modalities of treatment can decrease mortality significantly and the child may grow normally.
\end{abstract}

Key words: Hurler, $\alpha$-L-iduronidase;Lorinidase.

\section{Introduction}

Hurler syndrome is an autosomal recessive disorder of mucopolysaccharide metabolism caused by a deficiency of the enzyme $\alpha$-L-iduronidase ${ }^{1}$. The inability to degrade these macromolecules, results in their storage in a variety of tissues including the liver, spleen, heart, connective tissue and others, resulting in premature death, usually by second decade of life. Hurler syndrome represents the classical prototype of a mucopolysaccharide disorder, with a very low prevalence of 1:100,000 births and no predilection for sex and ethnicity has been found ${ }^{2,3}$. The diagnosis is usually made between the age of 6 and 24 months with evidence of coarse facial features, prominent forehead with large tongue, hepatosplenomegaly, corneal cloudiness, skeletal deformities, joint stiffness, short stature, acquired cardiomyopathy and progressive lenticular enlargement with increased intracranial pressure caused by communicating hydrocephalus. We are presenting a case of 10 years male child with typical clinic and radiological features of Hurler Syndrome.

\section{The Case}

A ten years age male, product of a 'second degree' consanguineous marriage with delayed developmental milestones from Syangja district presented with painless, progressive diminution of vision (more during night) for the last two years duration. There was past history of recurrent chest infections. The family history was not significant.

On examination this child had short stature with the height of $93 \mathrm{cms}$ (less than $3^{\text {rd }}$ centile) and coarse facial features, prominent forehead, macroglossia, depressed nasal bridge, dental malocclusion and stiffness of joints (Figure 1). Respiratory examination revealed pectus carinatum deformity of chest wall with normal air entry and no added sounds.CVS examination revealed grade III systolic murmur over 
mitral area radiating to axilla. Abdomen was protruded with umbilical hernia and hepatosplenomegaly. CNS examination was normal. On investigation complete blood count was normal with normocytic normochromic RBC. LFT and RFT were normal. Ophthalmological examination showed corneal cloudiness with secondary glaucoma. IQ assessment revealed Borderline Mental Retardation.

Lateral and AP view of the skull radiograph showed features of dysostosis multiplex which included a large skull with thick Chest radiograph (PA and lateral view) showed oar-shaped ribs with narrowing at the end and sclerotic calvarium, sella turcica with $\mathrm{J}$ sign. (Figure 2) Hand-wrist radiograph showed bullet-shaped phalanges with proximal pointing of all metacarpals. Only five carpal bones were present on right side and six on left side, which is equivalent to bone age of six years of age. (Figure 3). Lateral view of spine X-Ray showed anterior beaking of T12 to L3 vertebra, X-ray hip showed acetabular dysplasia. (Figure 4)Echocardioraphy was done, which revealed thickened mitral valve leaflet with mild to moderate mitral regurgitation. No feature of cardiomyopathy was detected. Urine examination for increased amount of heparan sulfate and dermatan sulfate and blood for alpha-L-iduronidase enzyme activity to confirm the diagnosis could not be done as it was unavailable. Based on clinical and radiological finding diagnosis of Hurler syndrome was confirmed.

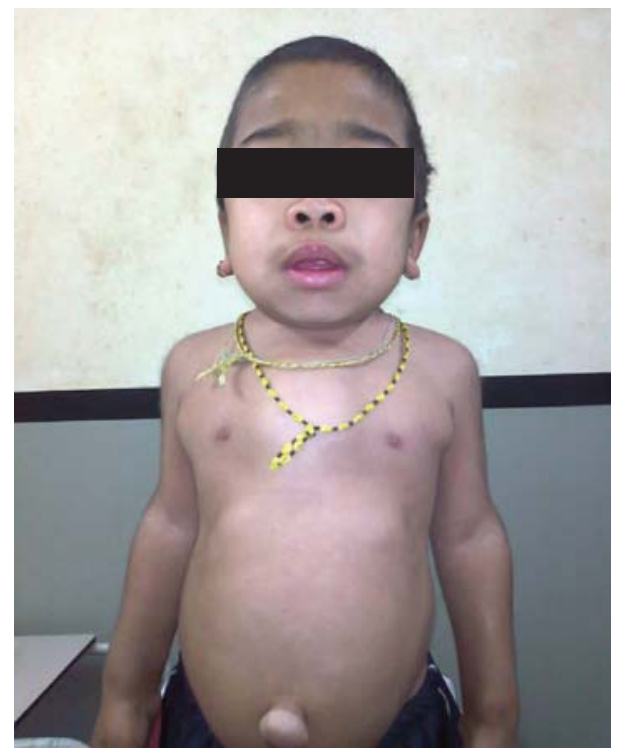

Fig 1: Coarse features with protuberant abdomen and umbilical hernia.

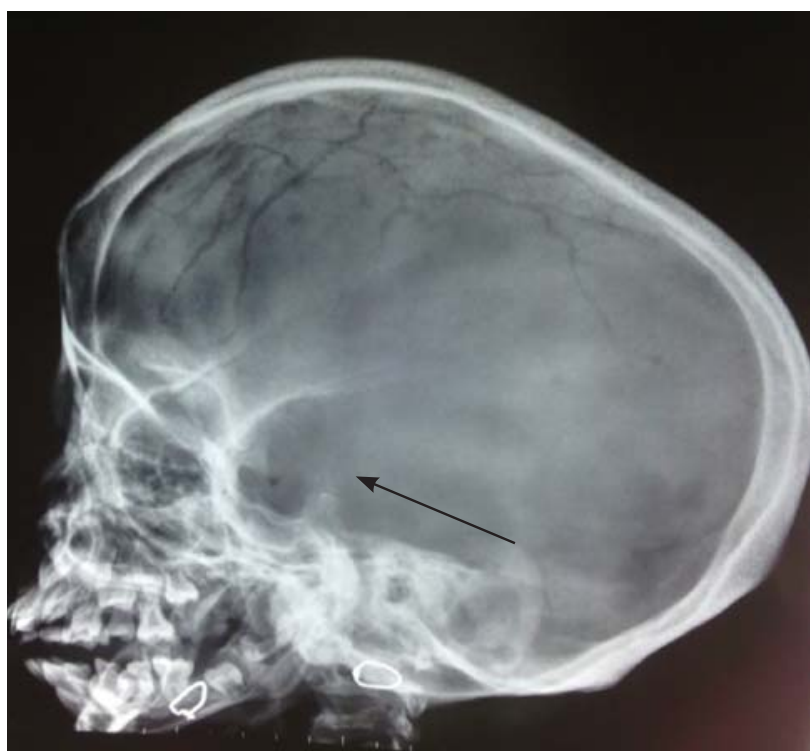

Fig 2: Lateral view skull with inverted $\mathrm{J}$ shaped sellaturcica.

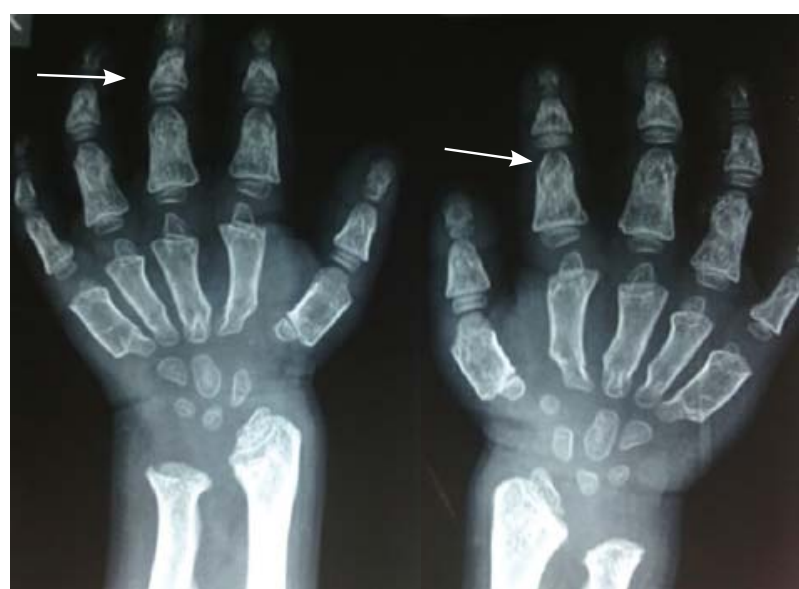

Fig 3: Both hands and wrist showing bullet shaped phalanges.

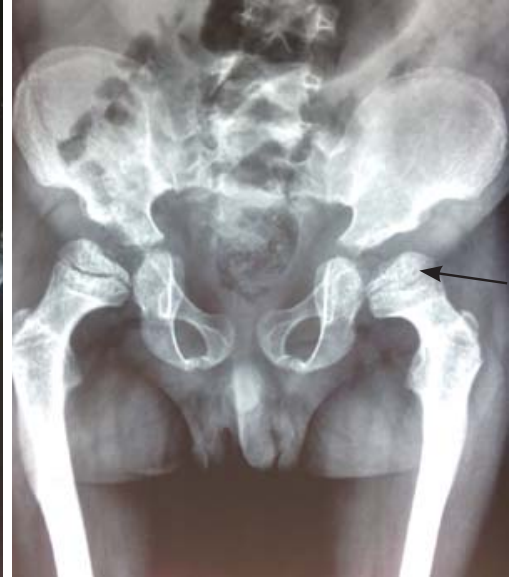

Fig 4: $X$ ray both hip AP view showing acetabular dysplasia.

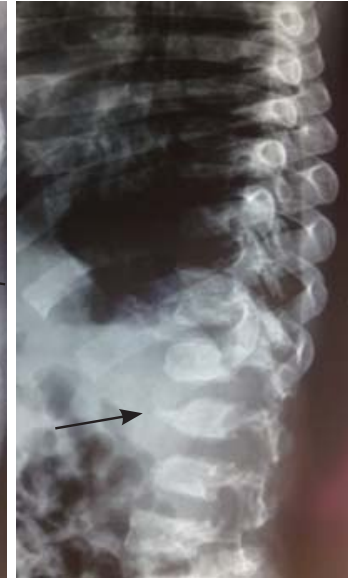

Fig 5: $X$ ray spine later view central beaking of $T 12$ to $L 3$ vertebrae 


\section{Discussion}

Hurler syndrome is an autosomal recessive disorder caused by deficiency of enzyme alpha-Liduronidase, which is responsible for the degradation of the glycosaminoglycans (GAGs), and its absence results into accumulation of heparan sulfate and dermatan sulfate in lysosomes of various tissues of the body, resulting in organ damage and causing mental retardation, stunted growth, skeletal deformities, stiff joints, corneal clouding, cardiorespiratory abnormality, thick lips, macroglossia with spaced and hypoplastic teeth, as observed in our case ${ }^{4}$.It is usually described in families with history of consanguinity, similar to our case $^{1}$. Deficiency of this enzyme results into a wide range of phenotypes including Hurler's (severe), Scheie's(mild) and Hurler-Scheie (intermediate) syndromes ${ }^{5}$. Diminution of vision as presenting feature in our case can be attributed to cloudiness of cornea.

Our patient had most of characteristic clinical and radiological features of hurler syndrome suggesting the diagnosis. The diagnosis could have been confirmed by a urine mucopolysaccharide excretion spot test and high-level glycosaminoglycans excretion in the urine, which could not be done due to unavaibility of tests.

Treatment modalities include Hematopoietic stem cell transplantation for child younger than 2 years of age suffering from Hurler syndrome with no or minimal central nervous system disease. Enzyme replacement therapy with $\alpha-L$ iduronidase is recommended for mild to moderate disease and for patients with neurological impairment ${ }^{6}$.To prevent mental retardation, a bone marrow transplant probably needs to be performed at a very early age. As the patient presented late these modalities of treatment cannot be suggested.

Laronidase (recombinant human $\alpha$-L-iduronidase) was the first enzyme replacement therapy approved for treatment since 2003 in USA and Europe. Clinical benefits include increased distance walked in sixminutes' walk test, improved forced vital capacity, decreased liver size and urinary GAG levels. Additional benefits include improved joint range of movement, decreased left ventricular hypertrophy and improved quality of life ${ }^{7,8}$. Iduronidase is given in a dose of 100U/ $\mathrm{kg} /$ week. Other modalities include Hematopoietic stem cell transplantation and other stem cell sources like umbilical cord blood, which has been proved safe and effective. It is much more easily available and requires less strict HLA match than bone marrow transplantation. ${ }^{9}$

As Hurler syndrome is autosomal recessive condition, it is important for couples with a family history of Hurler syndrome to undergo genetic counseling and genetic testing when they consider having children.

\section{Conclusion}

Mucopolysaccharidosis is rare metabolic disorders and a few case reports are published from Nepal. Diagnosis can be established withclinical and radiological features of Hurler syndrome even if molecular tests are not available.

\section{References}

1. Muenzer J. Mucopolysaccharidoses. AdvPediatr 1986;33:269-302.

2. Worth HM. Hurler's syndrome. A study of radiologic appearances in the jaws. Oral SurgOral Med Oral Pathol 1966;22:21-35.

3. Hingston EJ, Hunter ML, Hunter B, Drage N. Hurler's syndrome: Dental findings in a case treated with bone marrow transplantation in infancy. Int J Paediatr Dent 2006;16:207-12.

4. Spranger J. Mucopolysaccharidoses. In:Kliegman, Behrman, Stanton, editors, Nelson Textbook of Pediatrics. 19th editionvol.1 New Delhi: Elsevier; 2011. p. 511-512.

5. Muenzer J, Wraith JE, Clarke LA. The International Consensus Panel on the management and treatment of Mucopolysaccharidosis I. Pediatrics 2009;123:1929.

6. Muenzer J, Fisher A. Advances in the treatment of mucopolysaccharidosis type I. N Engl J Med 2004;350:1932-4.

7. Clarke L, Wraith JE, Beck $M$ et al. Long-term efficacy and safety of laronidase in the treatment of ofmucopolysaccharidosis I. Pediatrics 2009;123:22940.

8. Wraith JE, Clarke LA, Beck M et al. Enzyme replacement therapy for mucopolysaccharidosis I: a randomized, double-blinded, placebo-controlled, multinational study of recombinant human alpha-Liduronidase.J Pediatr 2004;144:581-8.

9. Staba SL, Escolar ML, Poe M et al. Cord blood transplants from unrelated donors in patients with Hurler's syndrome. N Engl J Med 2004;350:1960-9. 